\title{
Sembrar la reproducción de la vida en una comunidad tojolabal
}

\author{
Sow the reproduction of life in a Tojolabal community
}

\section{RENATA BÁEZ ROMERO}

Universidad Nacional Autónoma de México, Distrito Federal, México (renata.baez.romero@ gmail.com )(https://orcid.org/0000-0002-3227-3607)

\section{RESUMEN}

Los tojolabales son un pueblo originario ubicado en el estado de Chiapas en México, en el texto el objetivo es analizar la reproducción de la vida en los tojolabales de la comunidad Rafael Ramírez, a partir de un principio ético del trabajo comunal, en el komon 'a'tel, el cual implica compartir, servir, producir y reproducir de manera comunal, una práctica que se ha preservado a través de los siglos y que se opone al individualismo y egoísmo de la forma de producción capitalista.

\section{ABSTRACT}

The Tojolabales are an original people located in the state of Chiapas in Mexico, in the text the objective is to analyze the reproduction of life in the Tojolabales of the Rafael Ramírez community, based on an ethical principle of communal work, in the komon 'a'-tel, which implies sharing, serving, producing and reproducing in a communal way, a practice that has been preserved through the centuries and that opposes the individualism and selfishness of capitalist form of production.

\section{PALABRAS CLAVE / KEYWORDS}

tojolabales, trabajo, comunidad, Chiapas, reproducción, vida./ tojolabales, work, community, Chiapas, reproduction, life. 


\section{INTRODUCCIÓN}

La ética es orientadora, porque consiste en construir principios conceptuales, ontológicos y epistemológicos incluyentes de la diversidad humana, como: justicia, equidad, solidaridad, compromiso, responsabilidad, respeto, decoro, etc. Estos regulan las relaciones entre los individuos, la sociedad y la comunidad; busca aclarar y fundamentar la moralidad o eticidad, en el análisis y las prácticas de las costumbres morales, cotidianas, subjetivas en sociedad y en toda relación política y social humana. En la practicidad de los hechos o acontecimientos de las relaciones sociales; al aplicar y considerar como justo o injusto, correcto o incorrecto, bajo, o más bien desde los principios regulativos de la ética. A partir de la capacidad humana para orientar sus acciones y decisiones, con el bagaje ideológico alcanzado por creencias, valores y normas sociales compartidas por una determinada sociedad, en los ámbitos concretos de la actividad humana.

Los pueblos originarios vienen realizando históricamente, modelos de vida, a través de "formas que mantienen y refuerzan sus lazos comunitarios y sociales" (Villoro, 2001, p. 32). Las implicaciones que el conjunto de reivindicaciones y prácticas que llevan a cabo desde hace siglos tienen que ver con una reconsideración radical del marco de las relaciones en la forma de organización, producción, convivencia y coexistencia con la naturaleza y con los demás seres: jnantik lu'um (en tojol-ab'al) es un rubro sobre el cual se entreteje una compleja relación.

En este texto, hacemos una aproximación al modelo de vida comunal, en los tojolabales, en el caso específico de la comunidad Rafael Ramírez, del Municipio Las Margaritas en Chiapas, México. El modelo de vida de esta comunidad tojolabal se sustenta en un sistema de trabajo comunal, del komon 'a'tel (trabajo comunal) que se organiza a través de una política comunal, formas de cohesión para el trabajo, distribución de actividades y papeles culturalmente aceptados en función de trabajar con respeto y con la finalidad del bien común de todas y todos. Es decir, concordamos con la idea de Silvia Federici (2012) de concebir lo político desde una reproducción de la vida.

En este sentido, se analiza cómo el komon 'a'tel es un sistema de trabajo comunal con un fundamento ético en el pensamiento tojolabal, que por siglos ha subsistido a pesar de la agudización de formas capitalistas de minifundio, latifundio y de despojo de tierras, y que se sustenta en la riqueza concreta y se opone a una sobreexplotación del ser humano y de los bienes comunes, configurándose como una alternativa ante la crisis de los medios de socialización del trabajo, de la producción y distribución que afectan al ser humano y la naturaleza.

El desarrollo de la investigación se realizó a partir del método lógico inductivo ya que, a partir del análisis y estudio del caso particular, de los tojolabales de la comunidad de Rafael Ramírez en el municipio de Las Margaritas, Chiapas, México, la intención es construir ciertos principios generales. Como pueblo originario, los tojolabales, remiten su conocimiento a su pasado histórico-social y a la memoria, lo que se convierte en un asunto hermenéutico: “No sólo un conocimiento del pasado, sino dar un significado a lo [aparentemente para algunos] insignificante, hacer visible lo invisible." (Beuchot, 2006, p. 108). Por ello, también se hará uso desde la dialéctica, se analizarán las prácticas de los maya-tojolabales, sus conocimientos, saberes y prácticas, pero no de manera aislada, sino formando una continuidad y articulación 
en la manera en que sus formas de organización recuperan y articulan, el komon 'a'tel (trabajo comunal).

No se trata de un análisis únicamente teórico, porque no es "reducir lo social en su última instancia, a una realidad relacional" (Bagú, 1970, p. 81); desde la dialéctica implica una apertura epistemológica, es decir, no sólo se hará uso de la recopilación, análisis y manejo de diversas fuentes documentales escritas, sino para tener una comprensión más profunda, la apertura implica el uso de fuentes de carácter oral y testimonial, es decir la inclusión de las experiencias, conocimientos y aprendizajes que se tuvieron y se tiene con algunas familias e integrantes de esta comunidad, mismas que se integran con la autorización de las y los entrevistados.

\section{EL PUEBLO TOJOLABAL}

El nombre de tojolabales, deriva de su idioma, Ilamado tojol-ab'al', que significa idioma verdadero, se llaman a sí mismos tojolwinik'otik, además tojolabales significaría “los hombres legítimos o verdaderos" (C. Lenkersdorf, 1979, p. 275).

Los tojolabales es un grupo originario maya, asentado en la actualidad en el sureste de Chiapas $^{2}$. En un estudio sobre la lengua tojol-ab'al, el INALI, manifestaba el número de comunidades por municipio de la siguiente manera: "Las Margaritas: 209 comunidades; Altamirano: 79; Comitán de Domínguez: 45; La Independencia: 30; La Trinitaria: 10; Tenejapa: 5 y Ocosingo 1 comunidad" (INALI, 2008 en línea). En relación a la población, las cifras más aproximadas señalan una totalidad de 37, 667 (INEGI, 2004; Cuadriello y Megchún, 2006, p. 5). En cuanto al idioma, el último conteo que se tiene registrado por el INEGI (2015) refiere que el número de hablantes de tojol-ab'al, es de 55,442, de los cuales 27,809 son mujeres (INEGI, 2015 en línea).

Históricamente, se dio la experiencia de un autogobierno tojolabal en la zona fronteriza con Guatemala, reconocida como la "primera experiencia de autonomía indígena en la región" (Fuente de la, 2008, p. 65). Tuvo su nacimiento y desarrollo en el proyecto de la Unión de Ejidos de Pueblos Tojolabales (UEPT), la cual proyectó realizar desde dos años antes convocar a diversas asambleas y reuniones, en las que transmitía el proyecto de "reunificación" tojolabal hasta que llegado el momento se creó una forma de gobierno propia, un Consejo Tojolabal que se mantuvo en Asamblea Permanente, integrado por más de "300 miembros" (Hernández, 1999, p. 185). Asamblea que de 1986 a 1987 tomó decisiones colectivas que intentaban solucionar problemas entre ejidos y uniones ejidales, con una estructura de gobierno dividida de forma horizontal, lejos de jerarquías. En la experiencia

1 Es importante señalar que en el idioma tojol-ab'al no se escriben palabras con mayúsculas, esto se fundamenta, en que todos son iguales, hasta las palabras en tojol-ab’al, por eso al escribir no hace uso de mayúsculas. En los últimos años algunos lingüistas han modificado esto.

2 Ubicada en tres microrregiones distinguidas por las áreas ecológicas: "la región de los valles, -que abarca desde el centro hacia el extremo sureste del municipio de Las Margaritas-, la región de las tierras frías de Altamirano demarcada al norte por el afluente del río Tzaconejá-, y finalmente, la región de las cañadas de la selva lacandona, delimitada hacia el sur, en su porción más baja por el río Santo Domingo" (Cuadriello y Megchún, 2006, p. 5). 
del Consejo Tojolabal se puso en práctica la autonomía, ja'yipa tojol-ab’aly, "poder tojolabal", "poder verdadero", como señala uno de los participantes de este proyecto autonómico:

\begin{abstract}
Entendemos la autonomía tojolabal que impulsamos en la década de los ochenta como un proceso de recuperación del poder de nuestro pueblo; pero no de cualquier poder, sino de nuestros propios poderes, generados a través de nuestros propios medios, desde nuestra visión del mundo. La autonomía tojolabal fue concebida principalmente como un mecanismo de toma de decisiones, para resolver los múltiples problemas cotidianos a través de un gobierno tojolabal amplio, que buscaba la conciliación espiritual y política y el consenso entre las comunidades tojolabales (...) la autonomía la vivimos como la capacidad del ejercicio del derecho del pueblo tojolabal a decidir su propia vida presente y a diseñar su futuro (Hernández, 1999, p. 171).
\end{abstract}

En el caso situado de la comunidad Rafael Ramírez del municipio de Las Margaritas, su población es de 1075 habitantes (497 hombres y 578 mujeres) donde conviven tojolabales católicos y de otras religiones ${ }^{3}$.

En esta comunidad tojolabal corresponde únicamente a los hombres heredar las parcelas agrícolas, realizar actividades como desmonte de áreas para el cultivo, arar la tierra, construir viviendas, participar en asambleas o actuar como autoridad en su familia o comunidad. A las mujeres les corresponde realizar labores de reproducción y organización de la vida comunitaria como la preparación de alimentos, proveer de agua al hogar, el lavado de la ropa y la crianza de las/os hijas/os, asimismo, colaboran en el pastoreo, siembra, cosecha, entre otras.

Los tojolabales forman su visión ética de sí mismo y de los demás, a través de su cosmopercepción ${ }^{4}$ con base en la relación que tienen con la tierra: siendo hijos/as de ésta y hermanos/as de la flora y la fauna, rechazan actitudes de sometimiento, poder y dominación del entorno, mostrando gestos de respeto y cariño ante la naturaleza. Así su cosmopercepción implica una relación desde los cinco sentidos que posee el ser humano, se involucra con los demás [sea objetos o cosas] emotivamente, sensorialmente "tocándolas con los sentidos" (Rengifo, 2003, p. 72). Los sentidos así, permiten una comunión con los demás seres vivos sin mediaciones racionales que impidan vivir la vida tal como ella es, y los valores de respeto y cariño se extienden a la sociedad, es el reconocimiento como sujetos a aquellos que les rodea, de la "intersubjetividad” (Lenkersdorf, 2005, p. 39).

Desde la intersubjetividad, se deja de ser objeto de uso, para reconocerse como sujetos desde una relación horizontal, de igualdad y respeto mutuo; pero con deberes diversos, por lo cual la intersubjetividad no implica la homogeneidad, sino la diversidad para la complementariedad, donde nadie está por encima de los demás. El acontecer de la realidad hacia los tojolabales como civilización, no ha disminuido la prioridad que la tierra tiene en ellos/as como espacio privilegiado, sagrado, que no se limita a un espacio solamente de

3 Cabe precisar que Rafael Ramírez no pertenece a las comunidades zapatistas o afines al EZLN y sus proyectos autonómicos, sin embargo, entre la población existen simpatizantes hacia el zapatismo.

4 El concepto de cosmopercepción redefine nociones comunes que se aplican a todos los conocimientos de la vida, desde el dominio de la política, la economía, ciencia, religión, ética, moral y la filosofía (Ayala, 2011). 
reproducción de la vida, ya que mantiene un lugar fundante y un significado esencial en su civilización y forma de ver el mundo. Se toma conciencia ética, en palabras de Eliseo Reclus: "actuar consciente sobre la naturaleza, no de explotarla, ni de exterminarla, sino de respetarla." (1979, p. 39)

\section{EL SISTEMA DE TRABAJO DE EXPLOTACIÓN}

Antes de acercarnos al komon 'a'tel como un sistema de trabajo comunal, es preciso señalar cómo los y las tojolabales conciben las formas de explotación y las variantes de un modelo capitalista. En el diario de un joven tojolabal se mencionaba este modelo de vida:

1. 'ixtalajel. 'ajwalal sok moso [=] kapitalista sok 'a'tijum.

'ixtalajel b’a 'agrarya, b’a kontrobusyon. b’a 'eskwela. b’a

komersyo. b’a 'espital.

1. La explotación: patrón - mozo [corresponde a la de] capitalista-obrero.

La explotación [en sus formas distintas]: en la Secretaría de Reforma Agraria por

nuestras contribuciones [impuestos], en la escuela, en los comercios, en el hospital.

(Lenkersdorf, 2001, p. 306)

Históricamente la reforma agraria llegó de manera tardía al estado de Chiapas y las formas de trabajo semi-serviles se mantuvieron hasta finales de los años setenta del siglo XX. Una de las formas de trabajo que las comunidades tojolabales, tienen siempre en la memoria, en la tradición oral, es el baldío, que se configura temporalmente como una época anterior al reparto agrario; para ellos/as el tiempo de las haciendas, de los hacendados y latifundistas donde la generación mayor de abuelos, y aún de hijos estuvieron oprimidos, y trabajando "de balde" (Gómez y Ruz, 1992), es decir, sin pago o salario alguno fuese en especie o de forma monetaria.

El baldío está muy presente como una forma de producción, de explotación capitalista entre los y las tojolabales de mayor edad. En la actualidad, cuando existen condiciones de explotación en el trabajo, lo relacionan con la palabra 'ixtalajel, este concepto carga connotaciones negativas para ellos/as, pues significa que el "trabajador" recibe trato de juguete, es decir, de objeto y no de persona, es decir que al ser objeto su trato no se da de manera horizontal, sino de forma servil. Tal situación genera relaciones de trabajo desiguales, pues, es el mandón, patrón, quien ejerce el dominio y explotación sobre el sujeto, trabajador. que en la búsqueda de ganar un ingreso económico se ve atado muchas veces al ínfimo, salario recibido.

Para Lenkersdorf, una concepción del trabajo desde un modelo capitalista, es la tarega (2005, p. 132), es la tarea agrícola que se realiza fuera de la comunidad, en fincas o terrenos privados donde se recibe un salario por la actividad realizada. La tarega es sinónimo de explotación, porque si no se realiza en el tiempo estimado (de sol a sol), que la mayoría de las veces no se logra, el pago salarial se niega o se les da una cantidad menor a lo acordado. La tarega manifiesta una relación basada en el dinero, aquellos que se involucran en esta 
forma, se les nombra ganaranum (quienes ganan un sueldo y en su mayoría retornan a la comunidad) y reciben el tz'akol, salario obtenido, el cual a veces fructifica sólo en la familia, y no va más allá de la comunidad.

La inserción en este modelo de explotación, es una realidad en la comunidad de Rafael Ramírez, debido a los constantes cambios climáticos, la sequía, erosión de la tierra, la violencia política, etc., es decir, causas de orden ambiental, social, económico y político los ha llevado a migrar sea a la cabecera municipal de Las Margaritas, a Comitán, Chiapas, así como a la Ciudad de México o incluso a Estados Unidos. Como fenómeno social la migración incluye tanto a los varones quienes se insertan en el ámbito de la construcción, como ayudantes de albañilería y algunos como maestros albañiles, así como de las mujeres quienes se colocan en su mayoría como trabajadoras del hogar. Asumir el hecho de salir de su comunidad implica para ellos/as la búsqueda por conseguir un salario, como señala el hermano Alberto "mis hijos se van a México [la Ciudad de México] porque la sequía nos ha afectado" (Conversación con A. Velasco, 2017), o de la hermana Teresa: "voy a la ciudad a trabajar por una temporada, allá me quedo porque Rafael Ramírez está muy lejos del D.F." (Conversación con Teresa Jiménez, 2017). La necesidad implica el salir de la comunidad, no obstante, la mayoría de las veces la migración es temporal, y se migra siempre y cuando ya se haya hecho el komon'a'tel en la milpa y en la comunidad, de ahí que la migración sea temporal y se regrese a la comunidad para recoger la cosecha.

La caracterización del sistema capitalista como un régimen de explotación en las comunidades indígenas tojolabales, implica un síntoma de pobreza, entendida como desequilibrio y desigualdad:

\author{
2. jas yuj pobre'oktik. yuj ja smul ja jnal jumasa'. mey \\ ka'tjubtik. mixa wa xle'atik modo 'oj jtojb'es jb'ajtik. mi \\ xka'atik makunuk ja naturalesa yuj ja pilan pilan ‘aytiki. \\ mi xkolta jb'ajtik ja 'ixtalajumotik. \\ 2. ¿Por qué somos pobres? La causa son los ricos. No tenemos herramientas de \\ trabajo. Ya no nos esforzamos para mejorarnos; tampoco trabajamos para que la \\ naturaleza nos sea útil. La razón es que estamos divididos y nosotros los explotados \\ no nos ayudamos mutuamente. (Lenkersdorf, 2001, p. 306)
}

\title{
EL KOMON 'A'TEL COMO UN SISTEMA DE TRABAJO COMUNAL
}

El 'a'tel es definido como todo trabajo que está encaminado "al bien común de la comunidad" (Lenkersdorf, 2004, p. 203), no se considera como una tarea, es una acción que se relaciona con la tierra, es un trabajo por servir a la tierra kalajtik, es decir, a jnantik lu'um, (Nuestra Madre Tierra), y, además, en reciprocidad con nuestros hermanos necesitados. Por ello no se limita a las labores en la milpa, ya que se adaptan e integran diversas actividades de acuerdo a las necesidades de la comunidad, por ejemplo: la participación en el comité 
de educación, la participación en construcciones, la responsabilidad del comisariado, la coordinación de fiestas, marcar los linderos.

Por su parte el komon 'a'tel, (trabajo comunal), es la forma en que el 'a'tel se realiza, es parte de un sistema de gobierno comunal, que reproduce la vida cotidiana: "[un sistema de gobierno comunal es] las plurales tramas de hombres y mujeres que crean relaciones histórico-sociales que tienen cuerpo, fuerza y contenido en un espacio concreto: territorios comunales" (Tzul, 2016, p. 39).

El komon 'a'tel, es una práctica que las y los propios tojolabales han mantenido viva, y que a pesar de las múltiples vicisitudes se va perdiendo en otras comunidades tojolabales. La recuperación escritural más importante que desde ellos/as se hizo sobre el komon 'a'tel, es a través del diario de Sak K'inal Tajaltik, "nevado Ocotal" (su nombre en español: Javier Morales Aguilar) joven tojolabal quien murió en 1976 y que vivió en el ejido Puebla en Altamirano, Chiapas. Fue catequista y coordinador de la zona de Altamirano y asistió como oyente al primer Congreso Indígena en San Cristóbal de las Casas, Chiapas. Aunque se podría pensar que su cosmopercepción se veía influenciada sólo por su vocación de catequista, él mismo refiere la importancia de distinguir entre el ser catequista y el ser tojolabal:

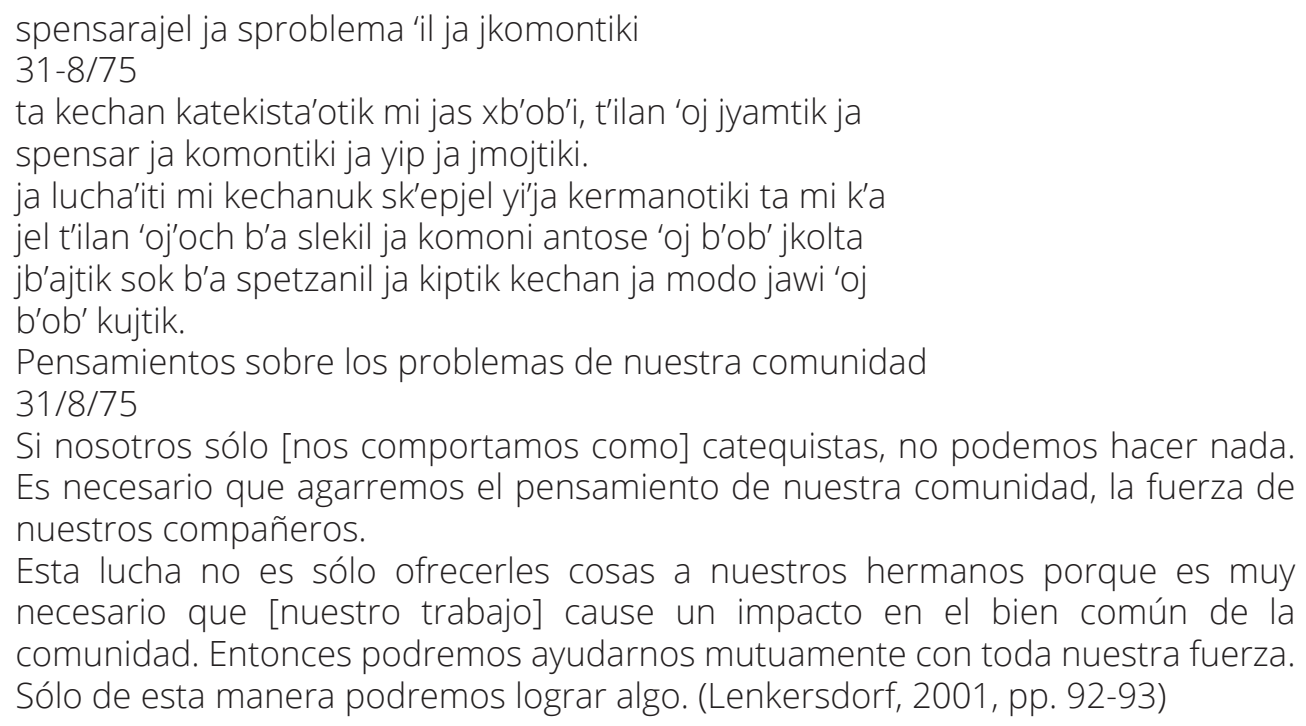

El komon 'a'tel, es un sistema comunal indígena que reproduce la vida, entendiendo la reproducción de la vida desde la acepción de Raquel Gutiérrez: “[...] procesos de producción, lazos y afectos de relaciones sociales de todo tipo, son los lugares que posibilitan la riqueza concreta que se gestan en medio de relaciones sociales no plenamente capitalistas y en permanente tensión con el capital" (Gutiérrez citada en Tzul, 2016: 49). El cual no fue destruido del todo por el proceso colonial, ya que ha trasgredido el tiempo, no sólo en el diario de Sak K'inal Tajaltik, sino que permanece en la comunidad de Rafael Ramírez, ahí se puede presentar como komon 'a'tel, trabajo comunal, como komon koltani, ayuda mutua, y como komon tsoman, unidos trabajando, los cuales se manifiestan en la comunidad a través de diversos trabajos colectivos. 
En Rafael Ramírez el komon 'a'tel, tiene un significado ético, es un principio que rige la vida comunal, como señalaba el tata Agustín: "si te ayudo yo ahora, pasado mañana, usted me va a ayudar a mí. El que tiene "buen sentido" apoya sin que le digas, no hay necesidad de avisarle, y tampoco hace falta el dinero, pues todos necesitamos la mano y fuerza de los demás. Es importante que la costumbre no se pierda" (Conversación con Agustín Santis, 2017). Tener "buen sentido" es la voluntad de acción, y como práctica se va difundiendo en la propia oralidad en la "costumbre", en la palabra y el ejemplo que se transmite en una relación intergeneracional: “Por eso el komon 'a'tel no se va a terminar, porque los nietos están aprendiendo ahora como es la movida (Conversación con Agustín Santis, 2017). komon 'a'tel como un principio fundado en la ética, genera valores morales en formas de trabajo, mismos que se originan en la oralidad. Los instrumentos de acción, los acuerdos son de palabra y voluntad, no es necesario establecer un contrato, un documento firmado por ambas partes. Por eso no es una relación jurídica la que se establece, sino un acuerdo de voluntad que se constituye por el valor de la palabra.

El komon 'a'tel no se remite a una sola práctica, sino que adquiere una diversidad, ya que también se puede entender como 'a'tel tsoman (ellos mismos lo traducen como: unidos a progresar) que se da en un ámbito de trabajo solidario: “Es decir, estamos todos (re)unidos en un solo trabajo" (conversación con Alberto Velasco, 2017). Y el carácter de esta diversidad de definiciones se basa en la oralidad y sobre las múltiples formas de realización. Como señala Lucía de Luna, al referirse al skoltajel jb'ajtik (ayudarnos entre nosotros), otra manera que retoma el komon 'a'tel (trabajo comunal):

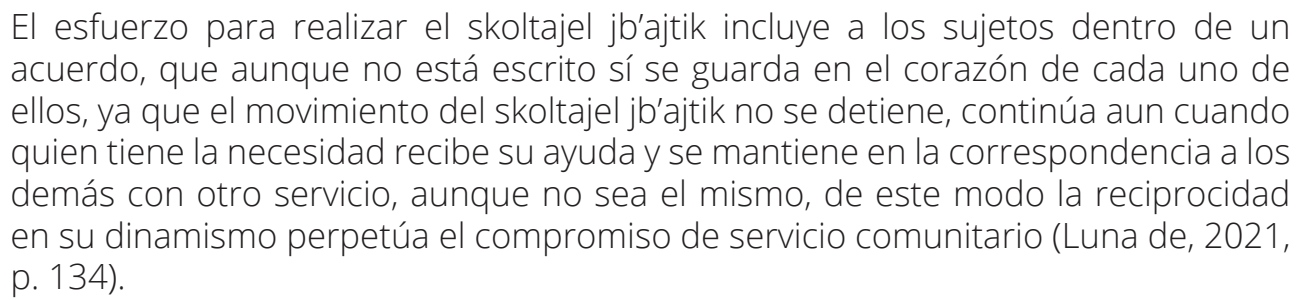

Es bajo el acuerdo del diálogo, de la palabra y voluntad, donde siempre se manifiesta si se realiza el trabajo comunal o en su caso se niega el mismo. Es decir, se respetan las individualidades, como platica Alberto Velasco, que la mayoría de las veces es preferible el trabajo comunal que el individual, sin embargo, hay algunas personas que en ocasiones prefieren trabajar solas en su milpa -quizás por cuestión de carácter-, por eso no solicitan ayuda. "Esto implica alargar el tiempo de trabajo hasta ocho días, porque cuando trabajan entre diez o quince personas se hace el mismo trabajo en un día o dos y es más alegre." (Conversación, 2017). El respeto a la forma de realizar las labores, implica que las formas de sociabilidad son de manera voluntaria y no por obligación.

La vigencia del komon 'a'tel, se confirmó de manera personal al ser partícipe en la siembra de maíz invitada por la hermana 5 Dominga Méndez Santis y con la aprobación de su familia

5 El sentido de inclusión en este sistema comunal indígena, de reproducción de la vida, se da en el nombramiento, aunque yo no soy tojolabal, ellos me aceptan como una más de la comunidad y se presenta al nombrarme hermana $\mathrm{y}$ al referirme a ellos como hermanas/ hermanos. 
y de los/as demás participantes de la comunidad. Las actividades comienzan desde antes de clarear el día, pues la milpa se encuentra a una hora de distancia y el acuerdo fue iniciar a las siete de la mañana. Se acordó reunirse puntualmente hombres y mujeres que participarían en la siembra del maíz.

Primero se reparten actividades, en total colaboraron cinco hombres y cinco mujeres (incluyéndome), lo que advierte de un sentido de paridad. Las mujeres son las encargadas de preparar los alimentos para la jornada (pozol [bebida hecha a base de maíz y agua], tortillas, frijoles y huevos fritos) los cuales se compartirán durante el almuerzo. Los demás integrantes de la familia alistan los instrumentos que se utilizarán en las actividades (la semilla, las macanas y el ganado). El terreno está listo para ser sembrado, pues fue rayado previamente con ayuda de la yunta. Una vez reunidos se forma un grupo de mujeres y otro de hombres preparados con semilla y macana en mano. Así dio inicio esta ardua labor, avanzando ágilmente por el mismo surco. Aunque es un trabajo agotador, el ambiente que se vive es de gusto, de alegría, entre bromas y cantos, permite mantener el entusiasmo paso a paso hasta la pausa que se hace para comer, refrescarse, descansar y convivir un momento. Nadie de los participantes realizó sus actividades con enfado, cada participante aceptó con voluntad las labores encomendadas y se realizó no solo una comunión en el trabajo, sino en el momento de compartir la comida. Después de eso se trabaja un rato más para concluir a las tres de la tarde. Los dueños del terreno agradecen a las y los participantes, y a la vez, se acuerda con ellas/os el horario para continuar al día siguiente y concluir con el resto del terreno por sembrar.

El trabajo es entonces que implica un gozo, un placer y alegría:

\begin{abstract}
La siembra se realiza entre pláticas, chistes y risas de quienes participan, sin prisas que los hagan hacer sus labores con descuido. Habrá como siempre tiempo para descansar sin presiones [...] para recobrar fuerzas y continuar sin pesares, pues es un momento para unirse material y espiritualmente con la madre tierra. Se trata de su colaboración en el proceso de la reproducción de la vida, la salud y la armonía comunitaria. Incluso después de la siembra se realizarán visitas continuas para escuchar por si necesita algo y así "la milpa no se sienta triste" (Luna de, 2021, p. 163).
\end{abstract}

Esta experiencia y práctica del komon 'a'tel se identifica como una trama comunitaria: "múltiples mundos de la vida humana que pueblan y generan el mundo bajo diversas pautas de respeto, colaboración, cariño, dignidad y reciprocidad, no plenamente sujetos a las lógicas de acumulación del capital, aunque agredidos y muchas veces agobiados por ellos (Gutiérrez, 2011, p. 23). Y como trama comunitaria implica una forma de "recuperar el cariño" (Grillo, Faiffer y Rengifo, 2017, p. 127) y de hacer otra forma de política, ya que parte de la tradición, pero se va renovando en cada circunstancia, una forma de hacer política que perdura a pesar de las disgregaciones y separaciones que las políticas y prácticas institucionales han insertado en la comunidad. 


\section{KOMON 'A'TEL, UNIDAD E INCLUSIÓN}

En Rafael Ramírez se hace unidad al trabajar la tierra, se trabaja el universo, ya que con el trabajo comunal en la agricultura mantienen una socialización con otras entidades. La alegría y el gozo nacen de la obra que se realiza y que es alimentar la vida misma, añade valor a la tierra y al ser humano, no es solamente pretensión sino encarnación de un valor moral. Por eso el sembrar el alimento, la comida, adquiere un valor trascendental: "la comida es vida" (Conversación con Olimpia Velasco L., 2017) y es mediante los trabajos comunales que los grupos sociales se manifiestan y se realizan en lo social y lo social para ellos adquiere un significado mayor, es el cosmos.

Mediante el trabajo en la milpa, es decir en la parcela, se mantienen relaciones sociales igualitarias y de reciprocidad entre diferentes hogares y comunidades, entre unidades reproductivas: "La constitución de las unidades reproductivas al interior de las comunidades indígenas, van a estructurar tramas familiares ampliadas que comparten trabajo y las necesidades comunales de reproducción de la vida." (Tzul Tzul; 2016, p. 5). Así como compartir los productos, lo que le da un valor social a la práctica del komon 'a'tel. La relación de la comunidad con la tierra, con el cultivo se manifiesta en analogías transmitidas por la oralidad, la comunidad es milpa como le manifestaban los/as tojolabales al Padre Ramón Castillo Aguilar:
La comunidad tojol ab'al es una milpa... En una milpa el primer surco es hombre, el segundo es mujer. Los surcos están sembrados en "tres bolillo": por donde quiera que los mirés forman surco; una mata va detrás de la otra; todas reciben el mismo calor y la misma humedad. Así es la comunidad: hombre y mujer, todos sus miembros tienen un nombre y uno después de otro debe servirla. (memorias, s/f, p. 32).

Desde su cosmopercepción para la reproducción de la vida, se da un sentido de paridad y complementariedad: hombre-mujer. La unidad básica es dos, por eso la reciprocidad es entre pares, no puede ser impar, dos es unidad. En Rafael Ramírez, la milpa se siembra en paridad, hombre-mujer intercalados uno y uno, buscando el equilibrio, la complementariedad: “Primero va un surco varón (winik), después un surco hembra (ixuk). Todas las matas van una después de la otra, todas a la misma distancia" (memorias Padre Ramón, s/f, p. 16). El sentido de mantener el intercalado significa equilibrio y al mismo tiempo es compartir e incluir, ya que para ello/as si la milpa se mantiene de esta manera se alimenta el corazón de los que siembran, de los surcos y de la madre tierra. Es decir, el komon 'a'tel conlleva a la inclusión, el equilibrio, el saber y cariño, una unidad de corazón: ja yaltzilal ja jnantik kinali: corazón de nuestra madre universo o naturaleza.

El komon ‘a’tel como sistema comunal es inclusión, socializar mediante el trabajo en la agricultura. Una práctica habitual es la de komon koltani (ayudar, cooperar), o koltanel (ayuda mutua), es decir, la ayuda que se brinda a quien lo necesita, así las unidades de reproducción (Tzul, 2016) implican que no precisamente el necesitado debe pertenecer al círculo familiar, traspasa ese límite y entonces implica que la comunidad se perciba como una gran familia. Regularmente esta práctica se manifiesta en los siguientes casos: 
-Cuando la mujer es viuda y no cuenta con el apoyo de sus hijas/os. ${ }^{6}$

.Cuando la persona es anciana y no le es posible realizar los trabajos sola/o.

.Cuando hay un integrante/s de la familia enfermo/as se puede solicitar ayuda adicional.

-También si no es suficiente con las/os integrantes de la familia es posible conseguir ayuda.

El komon 'a'tel como trabajo agrícola, requiere de varias jornadas de trabajo y se distribuyen de acuerdo a su edad y género. Las labores de cultivo se organizan bajo el mando del jefe de familia: los kerem jumasa u hombrecitos (varones desde los doce años y hasta que dejan de ser solteros), participan en todo tipo de labores agrícolas; los winikxa hombre enteros o casados (desde que se matrimonian hasta los sesenta años), les toca dirigir las actividades agrícolas, principalmente el arado y construir las piezas de las viviendas, entre otras tareas; a los tatametik (abuelos de más de 60 años) realizan tareas de menor esfuerzo como cuidado de ganado. Las mujeres por su parte participan en casi todas las actividades agrícolas excepto en el arado y desmonte de nuevas áreas de cultivo; las yal ak'ix (niñas) apoyan en las tareas domésticas; las ak'ix (solteras) realizan tareas agrícolas, llevar a moler el maíz, recoger y cargar leña, acarrear agua, limpiar el hogar; las ixukxa (mujeres casadas) en tareas agrícolas y domésticas y las méumetik (abuelas) en la preparación de alimentos y en el cuidado de los niños.

En el trabajo de la siembra, de la milpa, que incluye los productos del maíz, el frijol y otros productos, se da una participación de todos los miembros de la familia, de otros participantes de la comunidad, y en conjunto, mujeres, hombres, animales e instrumentos: “Unen su 'altsil -fuerza vital- al de los demás, para ser parte del 'a'tel -trabajo comunitariodonde lo más importante es que ja jnantik lu'um -nuestra madre tierra-se sienta contenta, perciba la alegría de los corazones de quienes se esfuerzan en trabajarla y cuidarla, para que de esa manera les corresponda con la alegría de sus frutos" (Luna de, 2021, p. 162).

Así podemos percibir, que se trata de la revisión de prácticas de distinción genérica, de las posiciones de diferenciación entre sujetos (hombres y mujeres), en actividades de interacción, es decir la división y distribución de actividades agrícolas y domésticas. Los trabajos realizados es así que son distribuidos entre los miembros de las familias, de las unidades de producción, de acuerdo a distinciones de edad y género. El ciclo agrícola comprende varias actividades como rozar, quemar, arar, sembrar maíz y frijol, regar, fertilizar, fumigar con agroquímicos, arrancar frijol, doblar, tapiscar y desgranar maíz. El aprendizaje de estas actividades se da desde la infancia a través del empleo y uso de herramientas que también conlleva una socialización genérica de las actividades desde la niñez.

\section{KOMON 'A'TEL COMO POLÍTICA COMUNAL}

Para Gladys Tzul, la política comunal, implica ocuparse principalmente de la reproducción de la vida, y “como los procesos de reproducción social requiere de formas de organización

6 Algunas veces los hijos/as se encuentran trabajando en la Ciudad de México por temporadas. Sin embargo, esto no impide que ellos vuelvan a su comunidad en ciertas fechas para apoyar en las labores agrícolas. 
social es preciso pensar desde el trabajo comunal. En las comunidades indígenas existen diversas formas, técnicas y tiempos de organizar el trabajo comunal" (2016, p. 6). Desde este horizonte, el komon 'a'tel implica una política para la vida, denota una delimitación espacialterritorial y un tiempo, no es el tiempo de trabajo común.

El tiempo difiere para los tojolabales, ellos señalan que no son dueños/as del tiempo, "no está a las órdenes de los hombres" (Lenkersdorf, 2005, p. 222). En este sentido el komon 'a'tel se orienta por el tiempo de la naturaleza, el tiempo de la siembra y el calendario se rige desde este ritmo, o estación para sembrar, no se acelera por el proceso de producción, porque no alteran el ritmo de la siembra, es decir se vive con paciencia, marca una distancia con el trabajo del sistema capitalista en donde la producción se constituye como el regidor del tiempo.

La comunidad de Rafael Ramírez, como otras comunidades tojolabales en Chiapas no se rige como otras ciudades de México por los horarios de verano y de invierno, sino que su tiempo, su horario no hace este cambio, su acontecer se guía por las actividades agrícolas, el conocimiento no es mediato sino mediado por la naturaleza, consiste en un rodeo y en una reflexión. Aunque con los cambios climáticos producidos en los últimos años, han provocado sequías, estaciones con demasiada lluvia, o la lluvia llega tardía, han modificado el inicio de la temporada de siembra. De ahí que no siempre es una fecha exacta, se ha dado un intervalo de días las estaciones oscilan, se dan aproximaciones entre ciertos días de iniciar las actividades, se concibe entonces desde un conocimiento empírico. Así, se da una comprensión de la experiencia y de la observación con paciencia y mesura, el iniciar la siembra cuando el tiempo-la estación climatológica lo permite, donde la variación puede llevar de un año a otro de cinco a ocho días de intervalo.

Al ser una política comunitaria, el komon 'a'tel, implica una transformación social "en el despliegue de la capacidad humana de producir y reproducir formas colectivas de habitar el mundo desde otro lugar que no es el de la dominación, la explotación y el despojo." (Gutiérrez y Salazar, 2019, p. 22). De producir el mayor grado de realización de la vida que una comunidad quiere, eso es lo que busca: una forma distinta de vivir y de organizar la vida desde una reproducción de la vida, como señala Silvia Federici (2012). De manera que se articula en un circuito de reciprocidad, en esencia, en el b'olmal (trueque), modalidad que se diferencia de intereses puramente comerciales, siendo su finalidad la satisfacción de una necesidad vital y no mercantil. Pues su uso se presenta como costumbre de intercambio de diversos productos, sin necesidad de emplear dinero, es un trabajo por la vida que no cuantifica ni comercializa las relaciones sociales.

Muchas veces el trueque es reproducido por las mujeres que siguen recordando esta valiosa práctica cultural, no obstante, en la actualidad también los hombres realizan b'olmal (trueque) de algunos productos ausentes en su comunidad debido a cuestiones climatológicas, o bien, porque no son propios de la región. Es decir, el trueque funciona en razón de cubrir alguna necesidad de la vida cotidiana, y al mismo tiempo, permite crear relaciones sociales con otras comunidades.

El b'olmal, como lo manifiesta el hermano Martín Velasco López, se sigue practicando en la actualidad:

A veces llegan personas a las casas con algunos productos, como son: ocote 
por frijol o maíz, limas por elote, ajo-puerro (cebolla verde, cebolleta) por chile, entre otros. Para el trueque usan sus propias medidas. Es bueno hacer trueque porque es una manera de no depender totalmente del dinero y al mismo tiempo se mantiene el vínculo con otras comunidades donde necesitan algún producto (Conversación, 2017).

Un sistema que produce bajo la necesidad del consumo regulado de la comunidad y busca si lo hay, una redistribución recíproca con otras comunidades, para lograr un bien para todos, el bien común, de una economía para y en reproducción de la vida que implica un principio de equidad, de equilibrio entre ser humano-ser humano y entre ser humanonaturaleza.

\section{CONCLUSIÓN}

El komon 'a'tel, el trabajo comunal es parte de un sistema de trabajo comunal, su recuperación y continuidad en Rafael Ramírez, reproduce relaciones de igualdad, "emparejamiento" entre todas y todos, "de igualdad, de estar parejos entre personas de diferente o igual sexo [prácticas que] perduran en las lenguas indígenas" (Olivera, Bermúdez y Arellano, 2014, p. 210). Para el jlekilaltik, una sociedad justa, en donde la reproducción de la vida, significa el bienestar económico para todas/os, en la medida de que se satisfacen las necesidades de todas/os de manera equilibrada, así como la libertad comunal.

El komon 'a'tel como trabajo comunal de unidades de producción, implica una dimensión esencial del ser humano, ser de diálogo y de comunión, donde el trabajo comunal se constituye en el nudo donde se juntan las relaciones sociales. Komon 'a'tel se da porque el otro importa, sin el/la otro/a no se es nada. La importancia de reconocerse en el/la otro/a, porque el/la otro/a no es lo contrario, ni lo jerarquizado, sino que es complementario, precautela el sentido de equilibrio, apoyo mutuo y reciprocidad entre hombres y mujeres, y con la producción, satisfacer las demandas crecientes en estrecha relación con la disposición de recursos, en las formas de organización social para procurarlos en beneficio común, de respeto y en apego a la naturaleza.

Además el komon 'a'tel, siembra una conciencia social de afecto, de amistad y gozo compartido entre los que participan de una actividad, es un acto de creación de lazos de afinidad y amistad recíproca no sólo entre seres humanos, sino de constante diálogo con la naturaleza y el universo, por lo cual, articula en su definición y realización una dimensión espiritual de convivencia y complementariedad, con el mundo natural y el mundo espiritual.

El komon 'a'tel implica una política, los valores morales se unen a los deberes políticos, al ser relaciones de reciprocidad que en la práctica son explícitas en un respeto mutuo. Es un principio general de la vida, al reproducir prácticas de reciprocidad y de inclusión, implica responsabilidad, compromiso consigo y con los/as demás, lo cual genera otra forma de hacer política, que se distancia de prácticas de un individualismo y en su lugar se constituyen y practican relaciones sociales para desarrollar el sentido de lo comunal. Ello implica que no se reduce a una forma de trabajo económico, sino que su alcance va más allá, ya que su raíz 
y sustento tiene principios éticos y busca su practicidad en formas económicas y en formas de relación social en el trabajo comunal. Como una práctica de reciprocidad no se limita a un mero intercambio de objetos, sino que implica practicar una interrelación de y entre sujetos con sujetos y con la naturaleza, dimensiones que en su practicidad conllevan a la complementariedad a establecer relaciones no jerárquicas, sino relaciones horizontales.

Es indudable que el komon 'a'tel se enfrenta a la injerencia fuera de la comunidad de Rafael Ramírez y de otras comunidades tojolabales, en el ámbito urbano y lejos de lo rural, a otras formas culturales y de trabajo, a otros principios éticos, principalmente aquellos valores como el individualismo, la competencia, la ganancia, lo mercantil por encima del apoyo mutuo. Para los tojolabales esto se manifiesta de distintas maneras, principalmente por necesidades económicas o de otra índole, lo que muchas veces ha significado la exclusión o desaparición parcial del komon 'a'tel.

\section{REFERENCIAS}

Ayala, José Luis. (2011). Diccionario de la cosmopercepción andina. Religiosidad, jaqisofía y el universo andino. Perú: Grupo Editorial Arteidea.

Bagú, Sergio. (1970). Tiempo, realidad social y conocimiento. México: Siglo XXI Editores.

Beuchot, Mauricio. (2006). "La hermenéutica analógica y el sentido de la historia”, en Estudios filosóficos. LV (158).

Castillo Aguilar, Ramón. (s/f). Memorias. Comitán, Chiapas: inédito.

Cuadriello Olivos, Hadlyyn, y Rodrigo Megchún Rivera (2006). Tojolabales. México: CDI.

Federici, Silvia (2012). Calibán y la bruja. Mujeres, cuerpo y acumulación originaria. Madrid: Traficantes de sueños.

Fuente de la, Rosa, (2008). La autonomía indígena en Chiapas. Un nuevo imaginario socioespacial, Madrid, Los libros de la Catarata.

Gómez Hernández, Antonio y Mario Humberto Ruz (eds.) (1992). Memoria baldía. Los tojolabales y las fincas. Testimonios, México: UNAM/ Universidad Autónoma de Chiapas.

Grillo, Eduardo; Gladys Faiffer y Rengifo, Grimaldo. (2017). Contra la peste, Recuperar el cariño. México: El Rebozo.

Gutiérrez Aguilar, Raquel. (2011), “Pistas reflexivas para orientarnos en una turbulenta época de peligro" en Gutiérrez Aguilar Raquel (Ed.) Palabras para tejernos, resistir y transformar en la época que estamos viviendo, Oaxaca-Puebla: Pez en el Árbol.

Gutiérrez Aguilar Raquel, y Salazar Lohman, Huáscar. (2019) "Reproducción comunitaria de la vida. Pensando la transformación social en el presente." VV.AA. Producir lo común Entramados comunitarios y luchas por la vida. Madrid: Traficantes de sueños.

Hernández Cruz, Antonio, (1999). "Autonomía tojolabal: génesis de un proceso", en Burguete Cal y Mayor (ed.), México: experiencias de autonomía indígena, Guatemala: Documento Número 28, IWGIA, pp. 171-191.

INEGI, (2004). La población hablante de lengua indígena de Chiapas, México, en línea www. inegi.gob.mx (consulta, 10/ octubre/ 2020)

INEGI, (2015). Lenguas indígenas en México y hablantes de (3 años y más) al 2015, en línea, www.inegi.org.mx/hipertexto/todas_lenguas.htm (consulta: 19/ octubre/ 2020). 
INALI, (2008). Catálogo de Lenguas Indígenas Nacionales, en línea, http://www.inali.gob.mx/ consulta:4/ noviembre/ 2020).

Lenkersdorf, Carlos. (2005). Filosofar en clave tojolabal. México: Miguel Ángel Porrúa.

Lenkersdorf, Carlos. (2004). Conceptos tojolabales de filosofía y del altermundo, México: Plaza y Valdés.

Lenkersdorf, Carlos. (2001). El diario de un tojolabal, México: Plaza y Valdés.

Lenkersdorf, Carlos. (1979), b’omak'umal tojol ab'al- kastiya 1. Diccionario tojolabal-español. Vol. I, México: Nuestro Tiempo.

Olivera, Mercedes. Marina Bermúdez y Arellano, Mauricio. (2014). Subordinaciones estructurales de género. Las mujeres marginales de Chiapas frente a la crisis. Chiapas: Centro de Derechos de la Mujer de Chiapas, A.C./ Centro de Estudios Superiores de México y Centroamérica/ Juan Pablos Editor.

Luna, Ramírez, Lucía de. (2021). Justicia comunitaria: senderos del buen vivir entre aymaras y tojolabales, suman qama qamaña y jlekilaltik. México: UNAM/CIALC.

Reclus, Eliseo. (1979). Evolución y revolución. Barcelona: Ediciones de la piqueta.

Rengifo Vázquez, Grimaldo. (2003). La enseñanza es estar contento. Educación y afirmación cultural andina. Perú: Proyecto andino de Tecnologías Andinas.

Tzul Tzul, Gladys, E. (2016). Sistemas de Gobierno Comunal Indígena: mujeres y tramas de parentesco. Guatemala: Editorial Maya Wuj. SOCEE. Guatemala.

Villoro, Luis (2001). De la libertad a la comunidad. México: FCE/ITESM.

Fuentes orales: entrevistas y/o testimonios

Conversación con Alberto Velasco López. (2017). Comunidad Rafael Ramírez, Chiapas, México: 16 de febrero.

Conversación con Teresa Jiménez. (2017). Comunidad Rafael Ramírez, Chiapas, México: febrero.

Conversación con Olimpia Velasco López. (2017). Comunidad Rafael Ramírez, Chiapas, México: 22 de febrero.

Conversación con Agustín Santis López. (2017). Comunidad Rafael Ramírez, Chiapas, México: 26 de febrero.

Conversación con Martín Velasco López. (2017). Comunidad Rafael Ramírez, Chiapas, México: 08 de julio. 